Supporting Information for

\title{
Interplay Among Folding, Sequence, and Lipophilicity in the Antibacterial and Hemolytic Activities of $\alpha / \beta$-Peptides
}

\section{Margaret A. Schmitt, Bernard Weisblum, and Samuel H. Gellman*}

NMR Data for $\alpha / \beta$-peptide 6:

Table S1: NMR Chemical Shifts Data for 6 in methanol- $\mathrm{d}_{3}$ relative to DSS (0.0 ppm).

In the following table, a "?" indicates that resonance dispersion was insufficient to unambiguously assign the chemical shift of the indicated proton(s).

\begin{tabular}{|c|c|c|c|c|}
\hline$\alpha / \beta$-Peptide $\mathbf{6}$ & $\mathrm{HN}$ & $\mathrm{H} \alpha$ & $\mathrm{H} \beta$ & Other \\
\hline N-Terminus & & & & $\mathrm{CH}_{3}: 2.02$ \\
\hline APC 1 & 8.70 & 3.15 & 4.73 & \\
\hline Phe 2 & 8.86 & 4.41 & 3.09 & HAr: 7.28 \\
\hline ACPC 3 & 8.37 & 2.66 & 4.58 & \\
\hline Leu 4 & 8.45 & 3.95 & $1.67,1.58$ & $\begin{array}{l}\mathrm{H} \gamma: 1.77 \\
\mathrm{H}: 0.94\end{array}$ \\
\hline APC 5 & 8.10 & 3.47 & 5.17 & \\
\hline Leu 6 & 8.72 & 3.89 & $1.70,1.53$ & $\mathrm{H} \gamma$ and $\mathrm{H} \delta: 0.89$ \\
\hline ACPC 7 & 8.44 & 2.90 & 4.69 & \\
\hline Phe 8 & 8.72 & 4.21 & 3.18 & HAr: 7.30 \\
\hline APC 9 & 7.99 & 3.38 & 4.96 & \\
\hline Phe 10 & 9.03 & 4.25 & 3.19 & HAr: 7.26 \\
\hline ACPC 11 & 8.60 & 2.83 & 4.40 & \\
\hline Lys 12 & 8.25 & 3.90 & 1.86 & $\begin{array}{l}\mathrm{H} \varepsilon: 2.91 \\
\mathrm{H} \delta: 1.70 \\
\mathrm{H} \gamma: 1.63,1.53\end{array}$ \\
\hline APC 13 & 7.80 & 3.34 & 4.77 & \\
\hline Leu 14 & 8.38 & 4.12 & $1.67,1.54$ & $\mathrm{H} \gamma$ and $\mathrm{H} \delta: 0.89$ \\
\hline ACPC 15 & 8.05 & 2.80 & 4.36 & \\
\hline C-Terminus & 7.51 , & & & \\
\hline
\end{tabular}

Figure S1: NOEs observed in $\alpha / \beta$-peptide $6\left(\mathrm{CD}_{3} \mathrm{OH}, 2 \mathrm{mM}\right)$

6

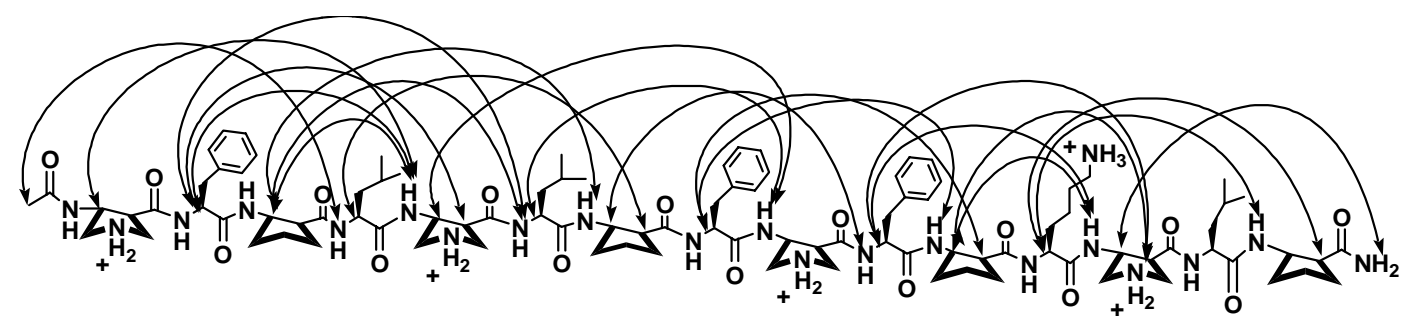


Table S2: NOEs observed in $\alpha / \beta$-peptide $6\left(\mathrm{CD}_{3} \mathrm{OH}, 2 \mathrm{mM}\right)$

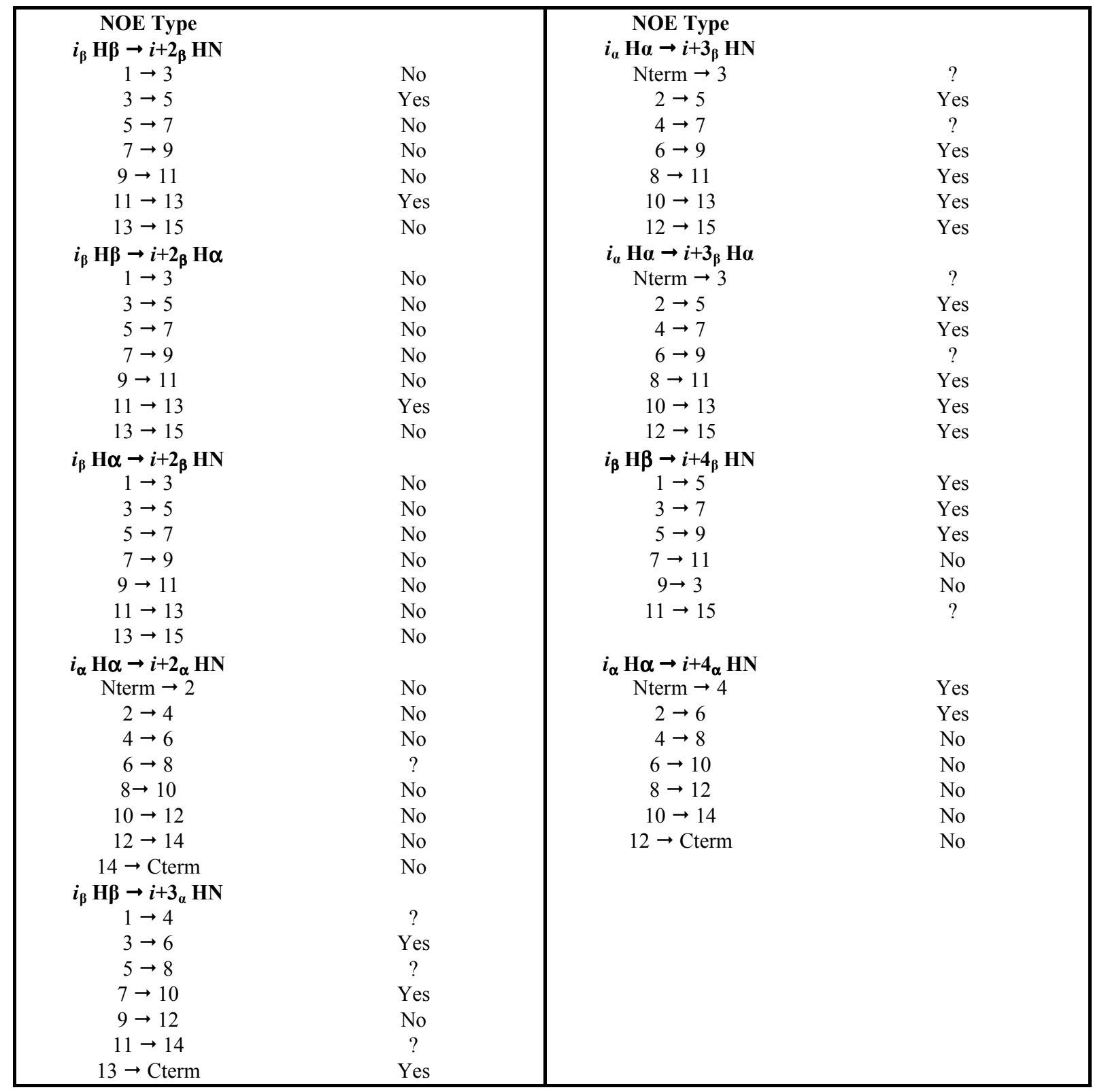

"Yes" indicates an NOE was observed that had only one possible assignment.

"Yes*" indicates an NOE was observed that had two or more possible assignments, one of which was consistent with the indicated nonsequential NOE. Other assignments for this NOE were not consistent with other probable NOEs.

"No" indicates that no NOE was observed, but that the indicated NOE would have been observable (i.e. not occluded by other NOEs) if it had been present.

"?" indicates that an NOE was observed, but that it could not be assigned because of overlap with either a sequential or intraresidue NOE, or that more than one probable nonsequential assignment for the NOE was possible. 
Figure S2: CD spectra of $\alpha / \beta$-peptides 1-9 in methanol

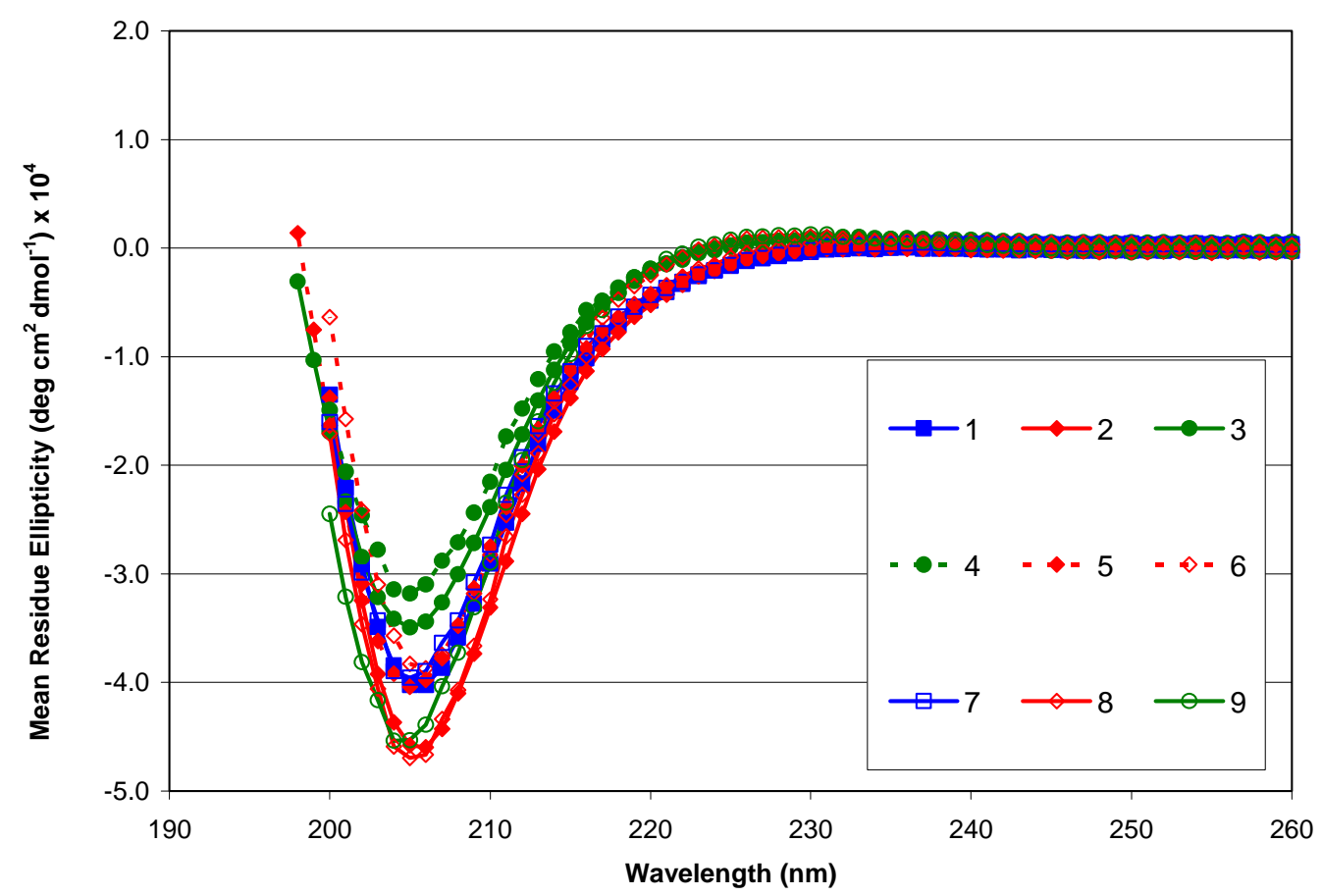

Figure S3: CD spectra of $\alpha / \beta$-peptides 1-9 in $10 \mathrm{mM}$ aqueous Tris buffer, $\mathrm{pH} 7.2$

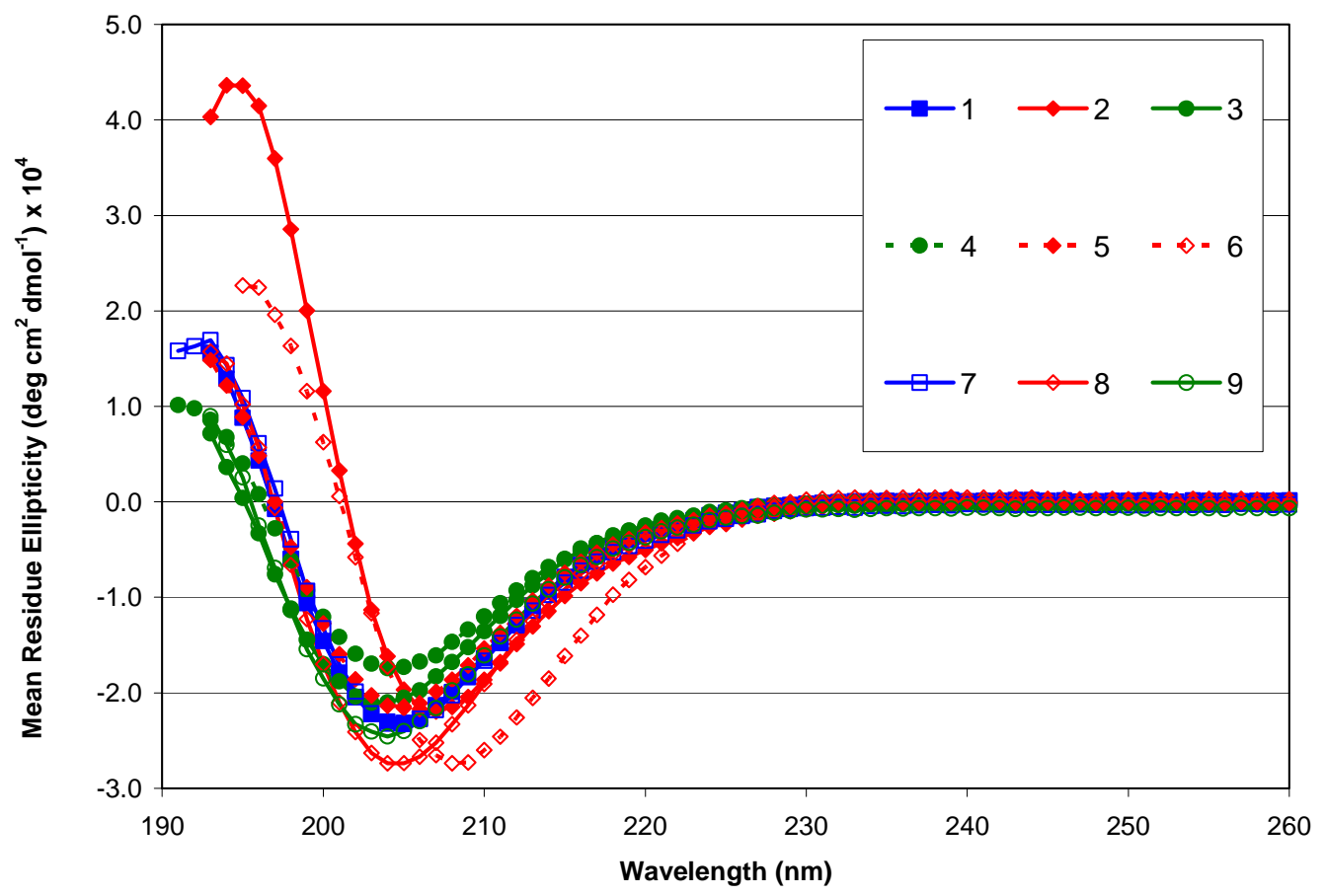


Figure S4: CD spectra for each $\alpha / \beta$-peptide in four solvents $(\mathrm{MeOH}, 10 \mathrm{mM}$ aqueous Tris buffer (pH 7.2), SDS micelles, and DPC micelles)

A: 1

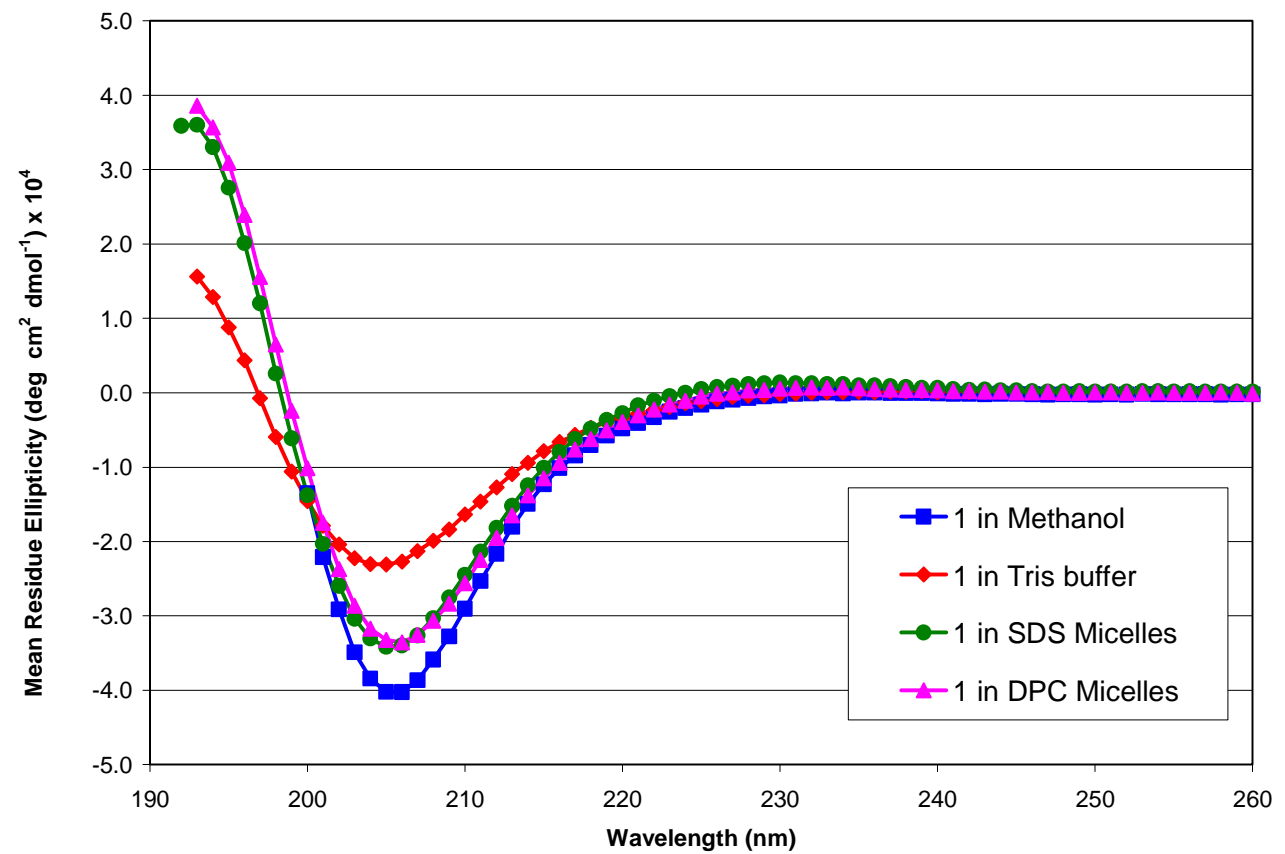

B: 2

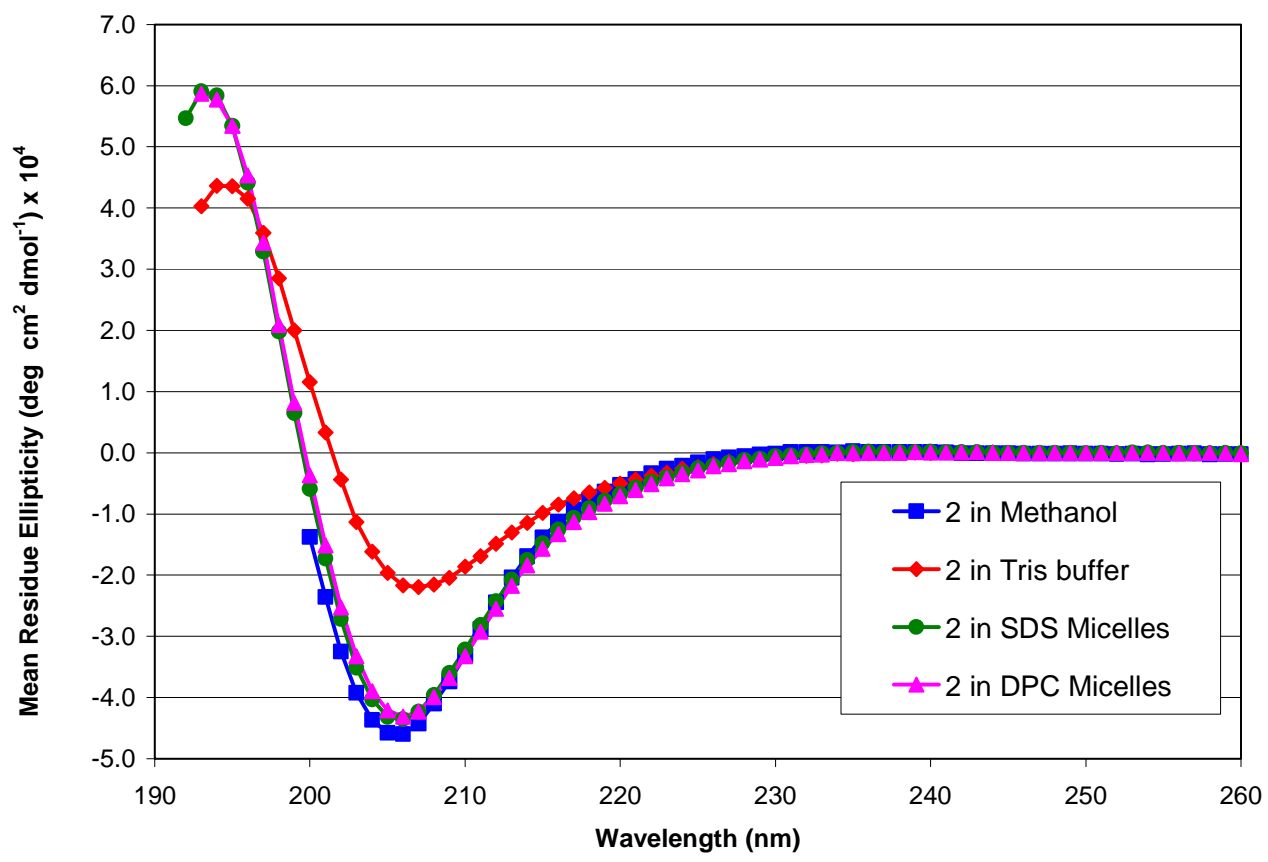


C: 3

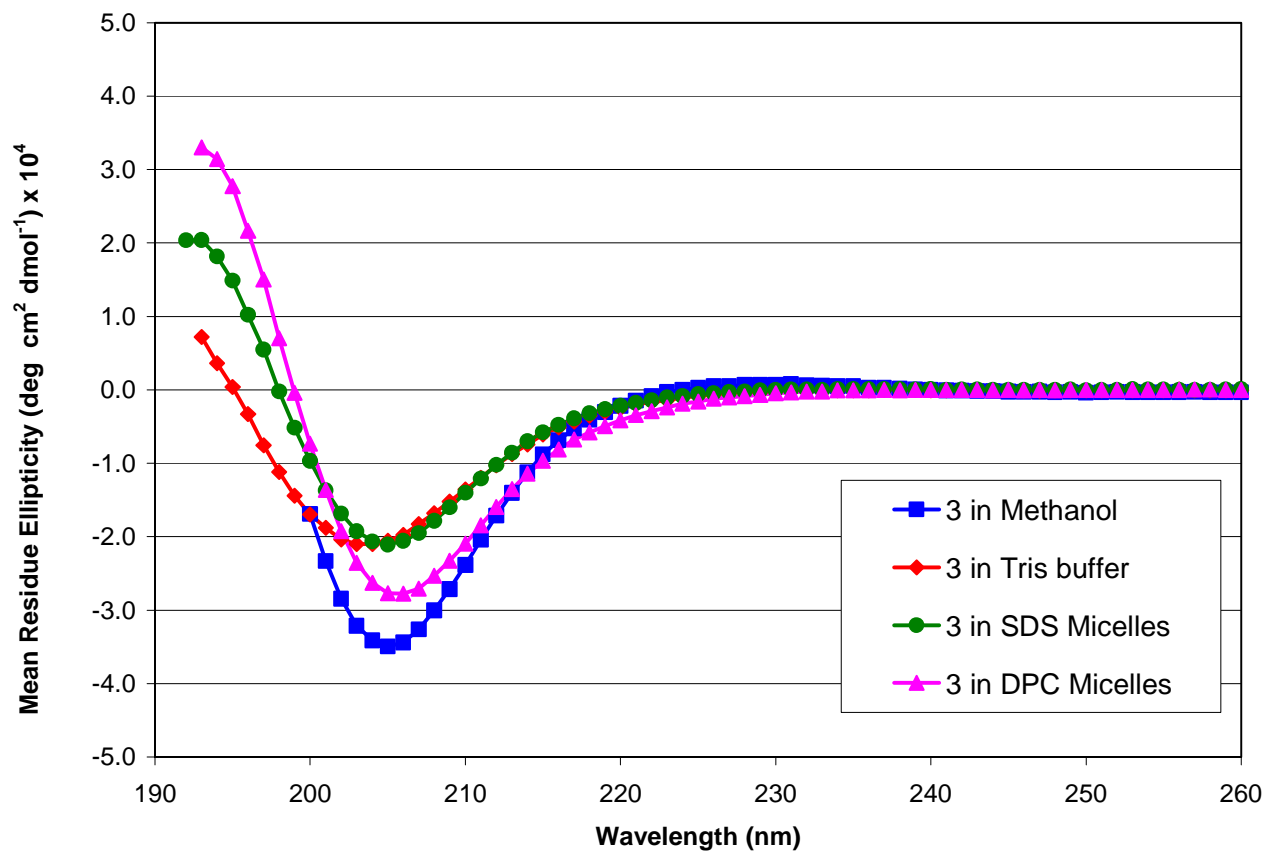

D: 4

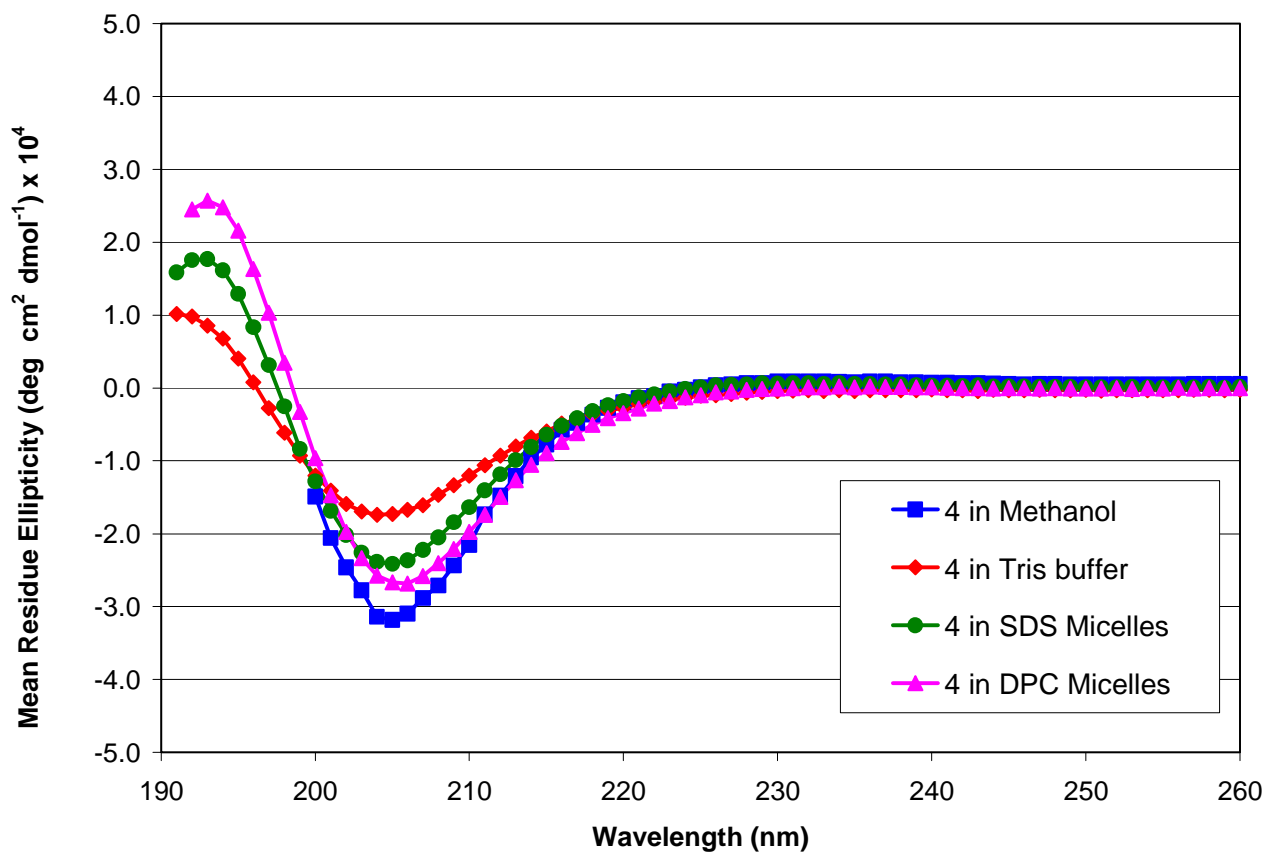


E: 5

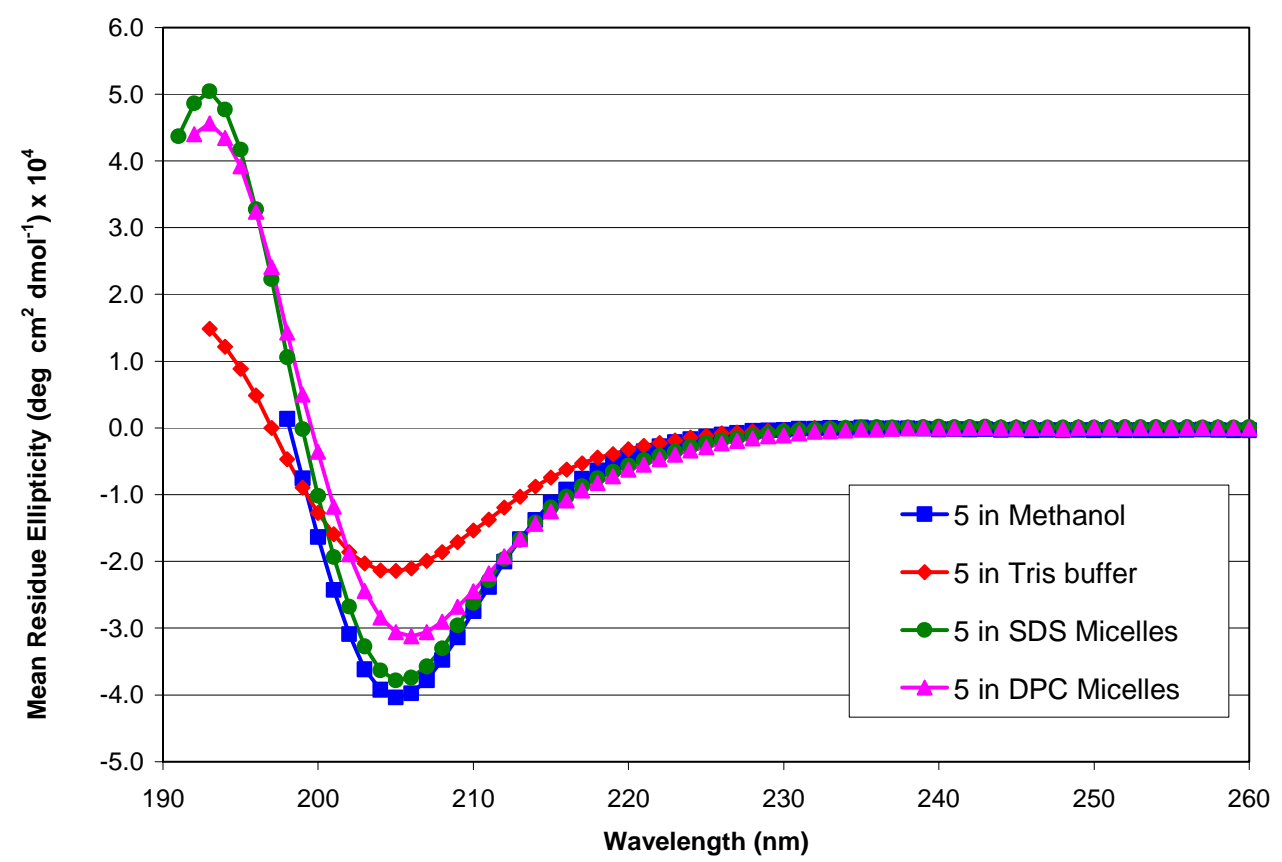

F: 6

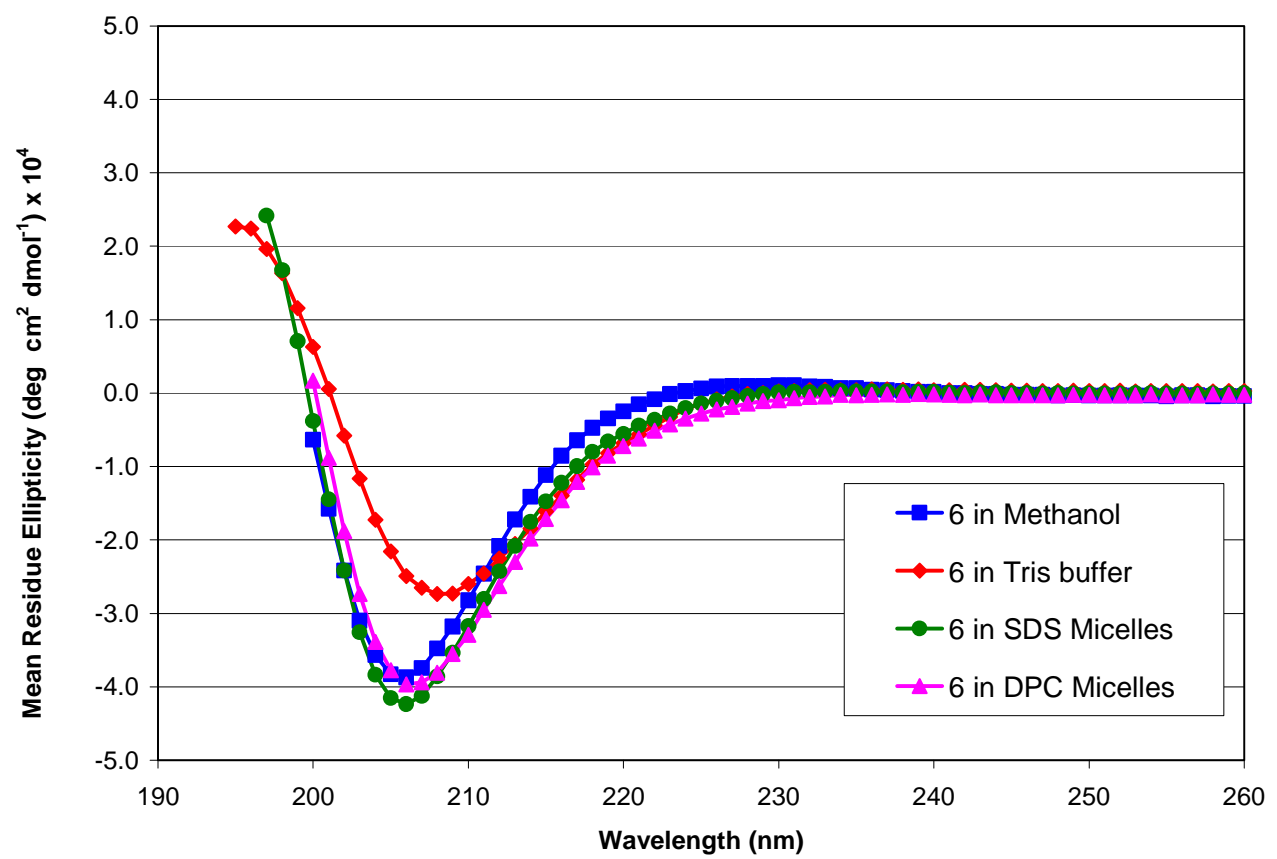


G: 7

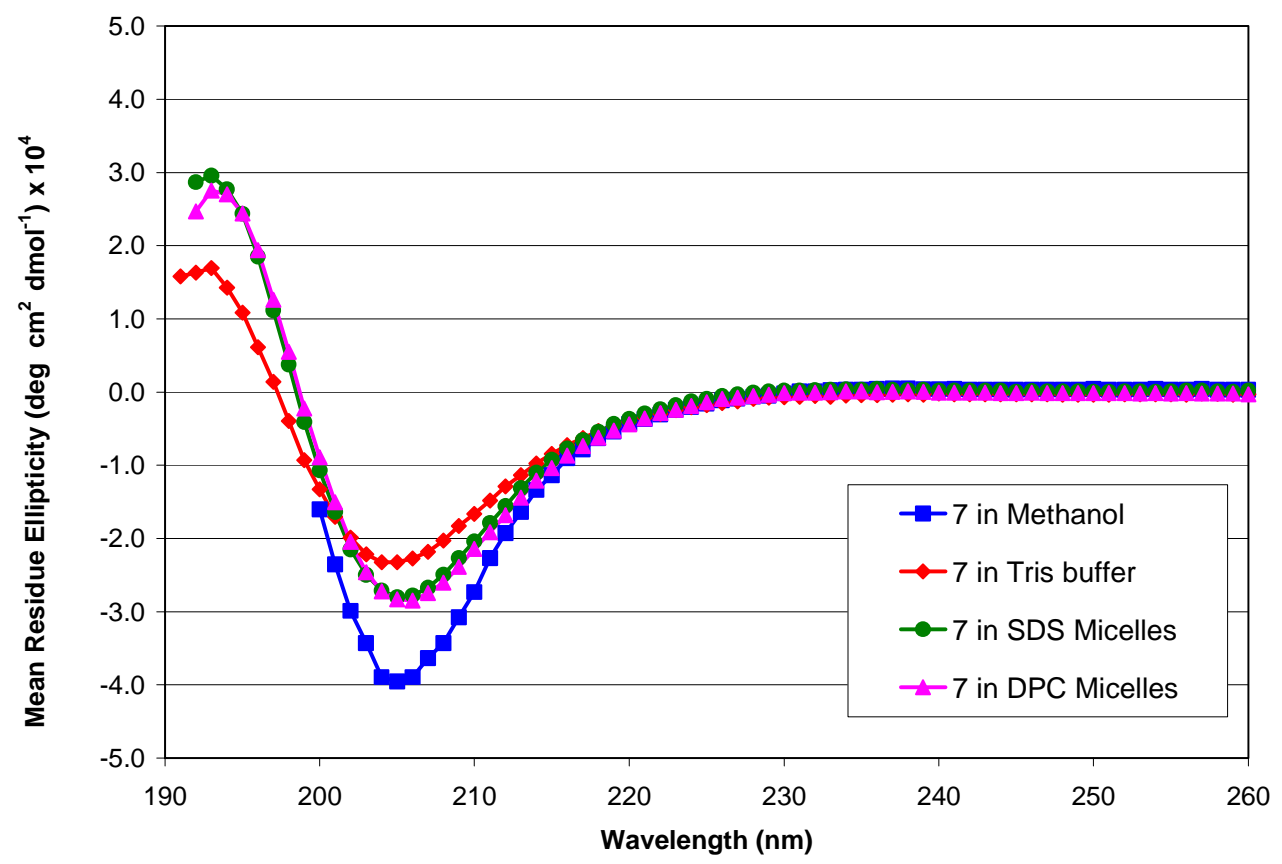

H: 8

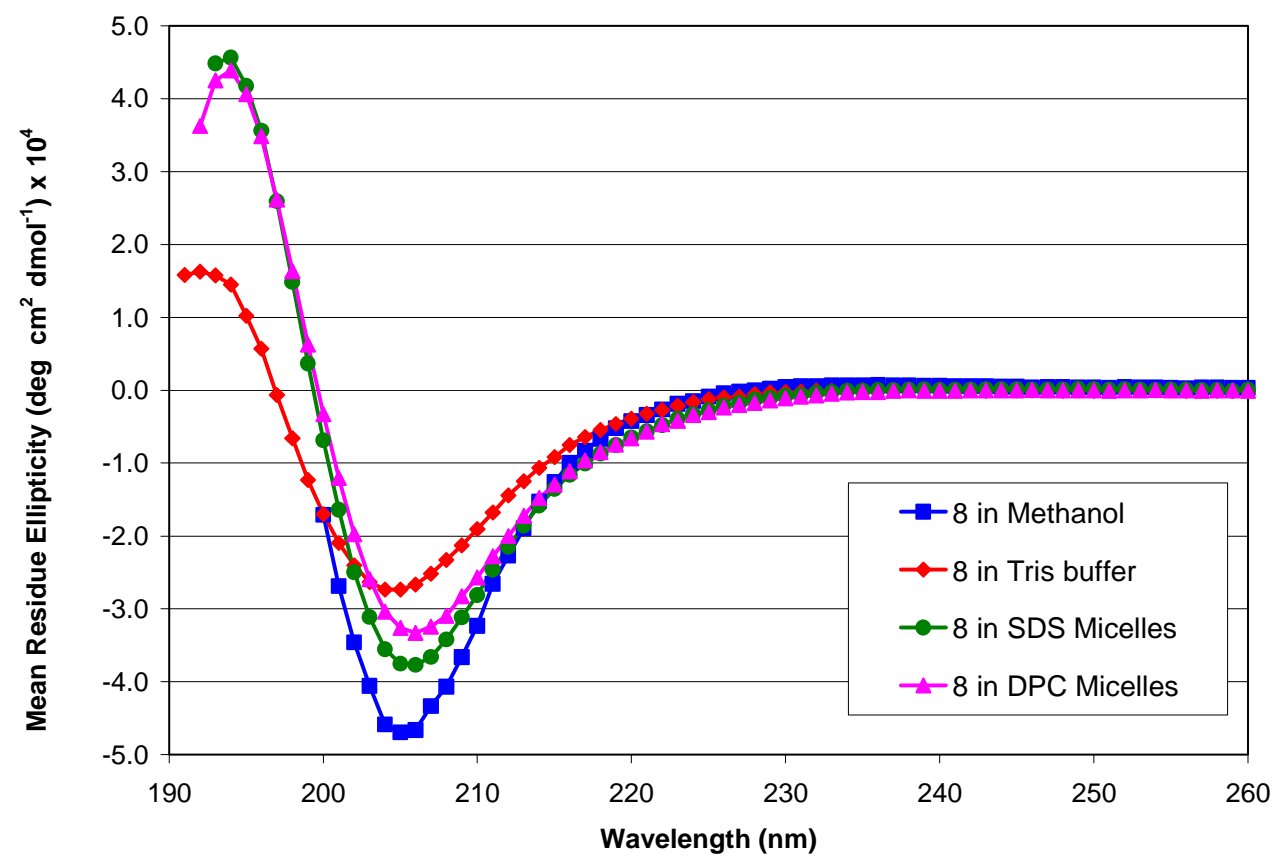


I: 9

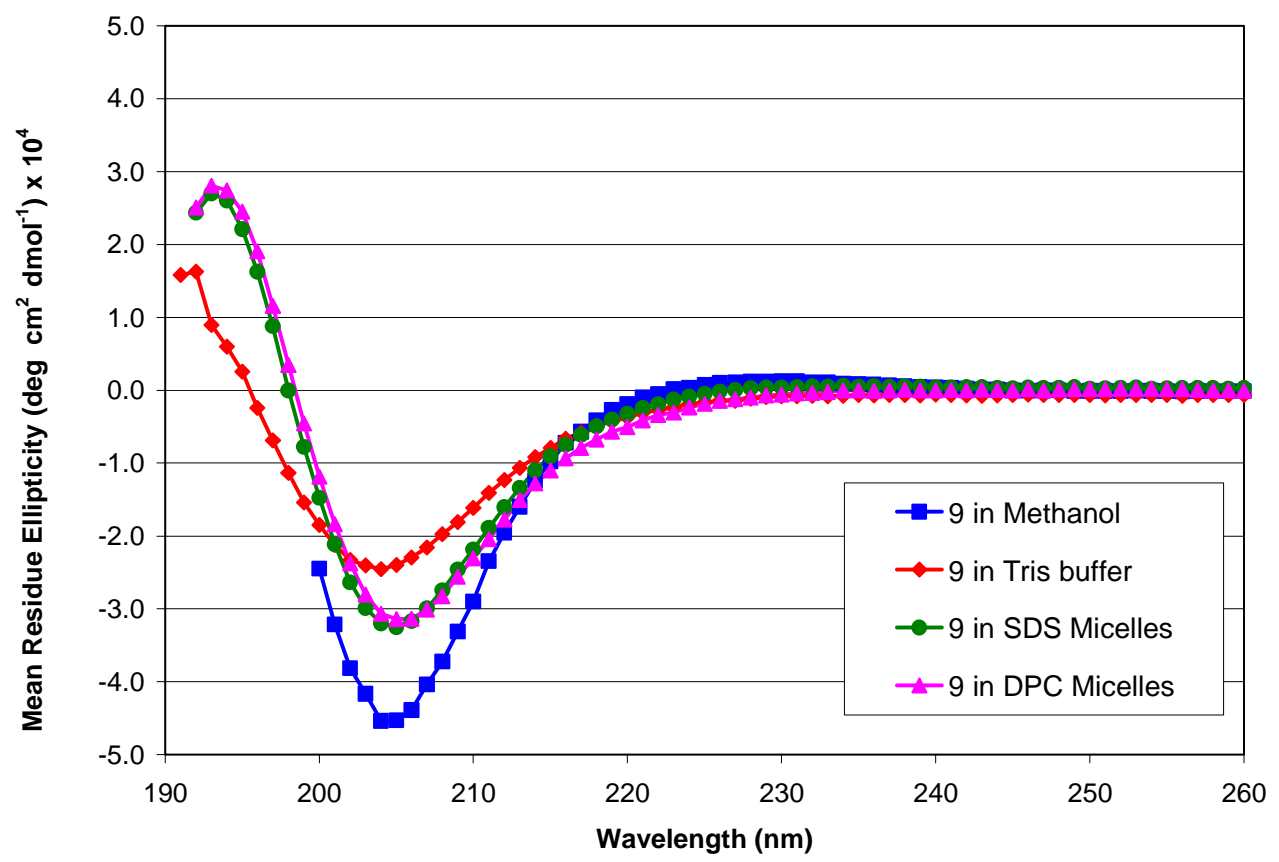

